\title{
1 Improvement of carotenoid extraction from a recently \\ 2 isolated, robust microalga, Tetraselmis sp. CTP4 \\ 3 (Chlorophyta)
}

4

5 Authors: Lisa M. Schüler ${ }^{1}$, Katkam N. Gangadhar ${ }^{1}$, Paulo Duarte ${ }^{1}$, Chloé Placines ${ }^{1}$, Ana 6 María Molina Márquez ${ }^{2}$, Rosa Léon-Bañares ${ }^{2}$, Vânia S. Sousa ${ }^{3}$, João Varela ${ }^{1}$ and Luísa 7 Barreira $^{1 *}$

$8{ }^{1}$ Centre of Marine Sciences, University of Algarve, Campus de Gambelas, 8005-139 Faro, 9 Portugal

$10{ }^{2}$ Department of Chemistry, Biochemistry, University of Huelva, Avda de las Fuerzas 11 Armadas s/n, 21071 Huelva, Spain

$12{ }^{3}$ CIMA, Faculty of Science and Technology, University of Algarve, Campus de Gambelas, 13 8005-139 Faro, Portugal

Funding The authors are indebted to the Foundation for Science and Technology (FCT), 21 Portugal for funding through CCMAR/Multi/04326/2013 research programme and a doctoral research grant (SFRH/BD/115325/2016) awarded to LS. Further funding was provided by the 0055 ALGARED+ 05 INTERREG V-A - España Portugal project. KNG also is thankful to the FCT and University of Algarve for financial support under the transitional rule of DecreeLaw no. 57/2016 as amended by Law No 57/2017. 


\section{Abstract}

In recent years, there has been increasing consumer interest on carotenoids particularly of marine sustainable origin with applications in the food, cosmeceutical, nutritional supplement and pharmaceutical industries. For instance, microalgae belonging to the genus Tetraselmis are known for their biotechnologically relevant carotenoid profile. The recently isolated marine microalgal strain Tetraselmis sp. CTP4 is a fast-growing, robust industrial strain, which has successfully been produced in $100-\mathrm{m}^{3}$ photobioreactors. However, there are no reports on total carotenoid contents from this strain belonging to T. striata/convolutae clade. Although, there are several reports on extraction methods targeting chlorophytes, extraction depends on the strength of cell coverings, solvent polarity and the nature of the targeted carotenoids. Therefore, this article evaluates different extraction methods targeting Tetraselmis sp. CTP4, a strain known to contain a mechanically resistant theca. Here, we propose a factorial experimental design to compare extraction of total carotenoids from wet and freeze-dried microalgal biomass using four different solvents (acetone, ethanol, methanol or tetrahydrofuran) in combination with two types of mechanical cell disruption (glass beads or dispersion). The extraction efficiency of the methods was assessed by pigment contents and profiles present in the extracts. Extraction of wet biomass by means of glass beadassisted cell disruption using tetrahydrofuran yielded the highest amounts of lutein and $\beta$ carotene $\left(622 \pm 40\right.$ and $618 \pm 32 \mu \mathrm{g} \mathrm{g}^{-1} \mathrm{DW}$, respectively). Although acetone was slightly less efficient then tetrahydrofuran, it is preferable due to its lower costs and toxicity.

\section{Keywords}

Marine microalgae, Glass beads, Lutein, RP-HPLC, Wet biomass 


\section{Introduction}

57 Carotenoids are synthesized by all photosynthetic organisms, as they play important roles in light harvesting and photoprotection [1]. They are composed of a 40-carbon isoprenoid backbone, responsible for colours ranging from yellow to red. Carotenoids are lipophilic compounds that can be divided into two groups: carotenes-non-oxygenated hydrocarbons (e.g., $\alpha$-carotene and $\beta$-carotene) - and xanthophylls-molecules containing oxygenated groups as, for example, lutein, violaxanthin, zeaxanthin and astaxanthin.

Recently, intensive research has been carried out to produce carotenoids from biological sources, mainly due to the importance of these pigments in terms of human health (e.g., decreased risk of degenerative and cardiovascular diseases, possible cancer prevention or cataracts) and nutrition [2-4]. Furthermore, carotenoids find their applications in biotechnology as antioxidants, colorants for aquaculture feed and food, as well as ingredients for cosmeceuticals and pharmaceuticals [5, 6]. Borowitzka et al. (2013) estimated the global market value of carotenoids to be about 1.2 billion USD, with $\beta$-carotene, lutein and astaxanthin representing approximately $60 \%$ of the total market. Microalgae are a promising biological resource of high-value biomolecules such as carotenoids, vitamins and polyunsaturated fatty acids [6]. These microscopic, mainly photosynthetic organisms, display high photosynthetic efficiencies, fast growth rates and are cultivated in large photobioreactors with high productivities of metabolites [8].

Carotenogenesis in microalgae occurs in the chloroplast from where the synthesized compounds are transported to different locations inside the cells. Carotenoids that are important for light-harvesting are located in thylakoid membranes, whereas other carotenoids, such as $\beta$-carotene and astaxanthin, are bound to lipids inside either cytosolic or plastidial lipid droplets, which may have a protective function by precluding the photooxidation of cellular components, in particular under unfavourable conditions [9, 10]. However, the precise location of biosynthesis and storage of a given carotenoid is highly dependent not only on the genetics of the microalgal strain, but also on the growth conditions. For an efficient extraction process, it is essential to ensure the complete disruption of the cell, including cell coverings, plasma and plastidial membranes, which are important barriers preventing the release of the pigments to the solvent. Furthermore, differences in the composition of these cell structures need to be considered. For example, 
primitive scales and known for its mechanical strength [11, 12]. Cell disruption can be achieved by mechanical (e.g., pestle/mortar, bead milling, ultrasound, and homogenizers) or non-mechanical (e.g., freezing/thawing, heating, osmotic shock, and alkaline lysis) methods [13]. Aside from efficient cell lysis, another crucial factor in any extraction procedure is the choice of the extracting solvent system. The ideal solvent needs to be able to penetrate the microalgal cells and show high affinity to carotenoids. Polar solvents such as acetone, ethanol and methanol extract xanthophylls more efficiently, whereas chloroform, hexane and tetrahydrofuran (THF) are non-polar solvents with higher affinity to carotenes and esterified carotenoids [14]. Besides the solubility of carotenoids in the solvents, its price and toxicity are important criteria for the selection of a given solvent for an industrial process. Moreover, it is important to minimize the degradation of carotenoids at all steps of the process. These pigments once outside the microalgal cell are very sensitive to UV radiation, oxygen and high temperature $[14,15]$. Although pigment extraction is a common effort in microalgal biotechnology, a literature search (Table 1) on extraction methods of microalgal carotenoids revealed the inexistence of a common extraction protocol. Furthermore, for the same genus different protocols are applied, highlighting the importance of the development of carotenoid extraction method for each microalgal strain. In this study, the microalga Tetraselmis sp. CTP4, a robust and euryhaline species, recently isolated from the Ria Formosa in Faro, Portugal was selected [16]. This fast-growing species displays lipid contents of up to $33 \%$ of its dry weight with properties suitable for biodiesel production [16]. Furthermore, it has been successfully grown semi-continuously in industrial photobioreactors and harvested by natural settling, resulting in a biomass paste with only $20 \%$ of water within 6 hours [17]. Thus, Tetraselmis sp. CTP4 is a good candidate for the co-production of biofuels and high-value products using a biorefinery approach. Therefore, the present work is focused on the optimization of carotenoid extraction, particularly the commercially important lutein and $\beta$ carotene from a mechanically robust microalga.

Table 1. Carotenoid extraction protocols from microalgal biomass found in the literature.

\begin{tabular}{lllll}
\hline Species & $\begin{array}{l}\text { Type of } \\
\text { biomass }\end{array}$ & Cell disruption & Solvent system & Ref. \\
\hline Chlorophyta & & & & \\
\hline Botryococcus braunii & freeze-dried & pestle and mortar & ethanol:water $(3: 1)$ & {$[18]$} \\
Chlorella vulgaris & freeze-dried & pestle and mortar & ethanol:water $(3: 1)$ & {$[18]$} \\
& & sonication & methanol:water $(9: 1)$ & {$[19]$} \\
& & glass beads & $100 \%$ acetone & {$[20]$}
\end{tabular}




\begin{tabular}{|c|c|c|c|c|}
\hline Chlorella zofingineses & freeze-dried & bead beating & $\begin{array}{l}\text { methanol:chloroform } \\
(2: 2.5)\end{array}$ & [21] \\
\hline Coelastrella sp. F50 & freeze-dried & bead beating & $\begin{array}{l}\text { methanol:dichlormethane } \\
(75: 25)\end{array}$ & [22] \\
\hline \multirow[t]{3}{*}{ Dunaliella salina } & freeze-dried & pestle and mortar, vortex & $\begin{array}{l}100 \% \text { acetone, hexane, } \\
10 \% \mathrm{NaCl}(2: 2: 1)\end{array}$ & [23] \\
\hline & wet & vortex $(5-10 \mathrm{~min})$ & acetone:water (8:2) & [24] \\
\hline & wet & $\begin{array}{l}\text { vortex }(10 \mathrm{~s}) \text { and sonication } \\
(10 \mathrm{~min})\end{array}$ & $\begin{array}{l}\text { methanol:chloroform } \\
(2: 2.5)\end{array}$ & [25] \\
\hline Dunaliella tertiolecta & freeze-dried & $\begin{array}{l}\text { mortar and sonication } \\
(10 \mathrm{~min})\end{array}$ & acetone $(8: 2)$ & [26] \\
\hline \multirow[t]{2}{*}{ Haematococcus pluvialis } & freeze-dried & pestle and mortar & $\begin{array}{l}\text { hexane/ ethyl acetate /hot } \\
\text { water }\end{array}$ & [18] \\
\hline & & glass beads & $100 \%$ acetone & [20] \\
\hline \multirow[t]{2}{*}{ Neochloris oleoabundans } & freeze-dried & pestle and mortar & ethanol:water (3:1) & [18] \\
\hline & & $\begin{array}{l}\text { cryogenic grinding, shaking } \\
\text { for } 3 \mathrm{~h} \text { at } 452 \mathrm{rpm}\end{array}$ & $100 \%$ acetone & [27] \\
\hline Parachlorella kessleri & freeze-dried & pestle and mortar & ethanol:water $(3: 1)$ & [18] \\
\hline Scenedesmus obliquus & freeze-dried & pestle and mortar & ethanol:water $(3: 1)$ & [18] \\
\hline \multirow[t]{2}{*}{ Tetraselmis chui } & frozen & $\begin{array}{l}\text { grinding and sonication } \\
(5 \mathrm{~min})\end{array}$ & acetone:water $(9: 1)$ & [28] \\
\hline & freeze-dried & pestle and mortar, vortex & $\begin{array}{l}100 \% \text { acetone, hexane, } \\
10 \% \mathrm{NaCl}(2: 2: 1)\end{array}$ & [23] \\
\hline Tetraselmis gracilis & frozen & $20 \mathrm{~h}$ & acetone:water $(9: 1)$ & [29] \\
\hline \multirow[t]{2}{*}{ Tetraselmis marina } & wet & $\begin{array}{l}\text { grinding and sonication } \\
(5 \mathrm{~min})\end{array}$ & acetone:water $(9: 1)$ & [28] \\
\hline & freeze dried & $65^{\circ} \mathrm{C}, 1 \mathrm{~h}$ & DMSO & [30] \\
\hline Tetraselmis rubens & frozen & $\begin{array}{l}\text { grinding and sonication } \\
(5 \mathrm{~min})\end{array}$ & acetone:water $(9: 1)$ & [28] \\
\hline Tetraselmis subcordiformis & frozen & $\begin{array}{l}\text { grinding and sonication } \\
(5 \mathrm{~min})\end{array}$ & acetone:water $(9: 1)$ & [28] \\
\hline \multirow[t]{10}{*}{ Tetraselmis suecica } & frozen & $\begin{array}{l}\text { grinding and sonication } \\
(5 \mathrm{~min})\end{array}$ & acetone:water $(9: 1)$ & [28] \\
\hline & freeze-dried & pestle and mortar & ethanol:water $(3: 1)$ & [18] \\
\hline & freeze-dried & sonication & methanol:water (9:1) & [19] \\
\hline & freeze-dried & pestle and mortar, vortex & $\begin{array}{l}100 \% \text { acetone, hexane, } \\
10 \% \mathrm{NaCl}(2: 2: 1)\end{array}$ & [23] \\
\hline & freeze-dried & 30 min incubation & ethanol:water (3:1) & [31] \\
\hline & frozen & & acetone:water $(9: 1)$ & {$[32]$} \\
\hline & frozen & sonication & methanol & [33] \\
\hline & frozen & $\begin{array}{l}\text { grinding and sonication } \\
(5 \mathrm{~min})\end{array}$ & $95 \%$ methanol & [34] \\
\hline & wet & sonication & acetone:water $(9: 1)$ & [35] \\
\hline & freeze-dried & $\begin{array}{l}\text { incubation of } 30 \mathrm{~min} \text {, } \\
\text { vortex, sonication } 10 \mathrm{~min} \\
\text { RT }\end{array}$ & acetone:methanol $(7: 3)$ & [36] \\
\hline \multirow[t]{2}{*}{ Tetraselmis tetrathele } & frozen & $\begin{array}{l}\text { grinding and sonication } \\
(5 \mathrm{~min})\end{array}$ & acetone:water $(9: 1)$ & [28] \\
\hline & wet & $60^{\circ} \mathrm{C}, 30 \mathrm{~min}$ & ethanol & [37] \\
\hline Tetraselmis wetseinii & frozen & & acetone: methanol $(7: 3)$ & {$[38$} \\
\hline Tetraselmis sp. & wet & sonication, $65^{\circ} \mathrm{C}, 30 \mathrm{~min}$ & ethanol & [39] \\
\hline
\end{tabular}




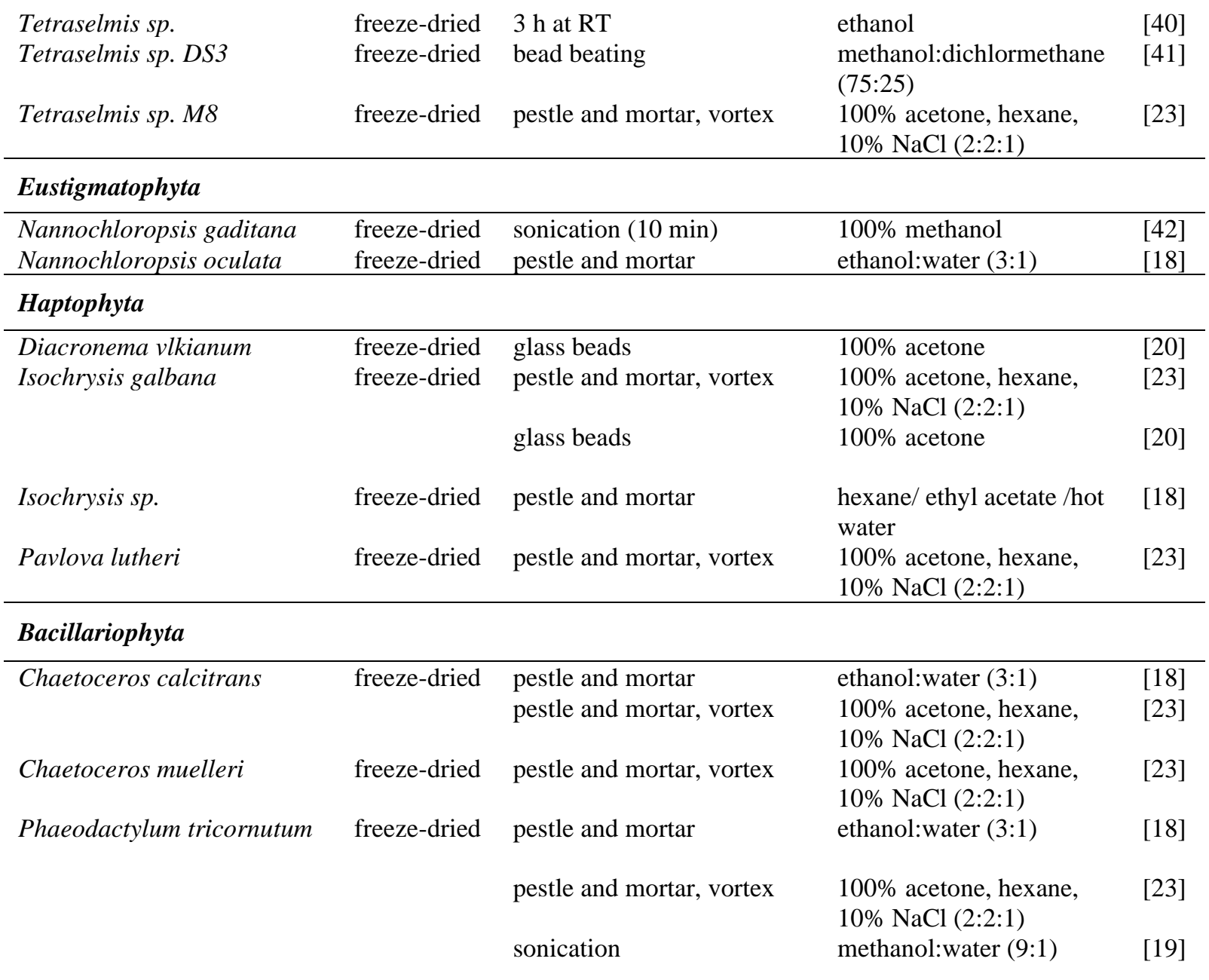

\section{Materials and Methods}

\section{Microalgal biomass}

120 Tetraselmis sp. CTP4 was cultivated in the laboratory as described previously [16, 43]. Upon

121 harvesting, the biomass was immediately frozen at $-20{ }^{\circ} \mathrm{C}$. Freeze-dried biomass was

122 obtained upon lyophilisation for $24 \mathrm{~h}$ and stored in a desiccator at room temperature in the

123 dark. Freeze-dried biomass can be made available upon request.

124 This article does not contain any studies with human participants or animals performed by 125 any of the authors.

127 Optimization of carotenoid extraction

128 Different conditions, such as type of biomass, cell disruption method and solvent, were tested 129 using a factorial experimental design to find the best method for extracting carotenoids from 130 Tetraselmis sp. CTP4 (Fig. 1). For that purpose, the extraction was conducted on both wet 131 and freeze-dried biomass with the use of four different extraction solvents - ethanol (EtOH), 
acetone, methanol (MeOH) and tetrahydrofuran (THF) — and with the application of different cell disruption methods-mechanical dispersion or glass bead milling. Extraction solvents were of analytical grade except for THF, which was of HPLC grade to ensure the absence of peroxides. During all extraction steps, samples were kept on ice and in the dark to avoid pigment degradation. For the extraction, about $3 \mathrm{mg}$ dry weight (DW) of each type of biomass were resuspended in $3 \mathrm{~mL}$ of ice-cold solvent. Afterwards, cells were lysed by means of mechanical dispersion using an IKA Ultra-Turrax T18D Basic apparatus (IKAWerke GmbH, Staufen, Germany) at $25000 \mathrm{rpm}$ during 2 cycles of $45 \mathrm{~s}$ or, alternatively, $0.7 \mathrm{~g}$ of glass beads $(425-600 \mu \mathrm{m})$ were added and tubes were vortexed on an IKA Vortex Genius 3 shaker (IKA-Werke GmbH, Staufen, Germany) at maximum speed for 2 min. UltraTurrax mechanical dispersion produces a considerably amount of heat. So, even though the samples were kept on ice throughout the whole process, this method was applied for a shorter period than bead milling. To collect the supernatant, samples were centrifuged at $10{ }^{\circ} \mathrm{C}$, $8000 \times g$ for $5 \mathrm{~min}$. The extraction procedure was repeated until both the pellet and the supernatant became colourless.

Extracts were combined and dried using a gentle nitrogen flow and resuspended in $5 \mathrm{~mL}$ of $100 \%$ acetone for spectrophotometric analysis of total chlorophyll and carotenoid content. The extraction protocols that yielded the best results in the spectrophotometric analysis were analysed by HPLC to assess the pigment profile. To this end, the extracts were dried, resuspended in methanol $(0.7 \mathrm{~mL})$ followed by filtration using PTFE filters $(0.2 \mu \mathrm{m})$. HPLC analysis was performed immediately after resuspension to avoid pigment degradation.

All experiments were carried out in triplicate and average values are reported. To determine significant differences, variance analysis (ANOVA) was performed at a confidence level of 95\% using Tukey HSD post-hoc test. These statistical tests were performed with SPSS (release 25.0, SPSS Inc., Chicago, IL) software.

\section{Determination of total chlorophyll and carotenoid contents}

\section{Spectrophotometric estimation of pigments}

The absorbance $\left(\mathrm{A}_{n n n}\right)$ of the extracts was measured by spectrophotometry in a Spectronic Unicam 3000 UV-Vis (Thermo Fisher Scientific, Waltham, Massachusetts, U.S.) at three different wavelengths - 662, 645 and $470 \mathrm{~nm}$ - to estimate their pigment composition. The concentrations of chlorophyll $a(\mathrm{Chl} a)$ and $b(\mathrm{Chl} b)$ and total carotenoids (TCar) in $\mu \mathrm{g} \mathrm{mL} \mathrm{m}^{-1}$ were estimated using the following equations [44]: 
Chl $a=11.75 \mathrm{~A}_{662}-2.35 \mathrm{~A}_{645}$

Chl $b=18.61 \mathrm{~A}_{645}-3.96 \mathrm{~A}_{662}$

$\mathrm{TCar}=\frac{1000 \mathrm{~A}_{470}-2.27 \mathrm{Chl} a-81.4 \mathrm{Chl} b}{227}$

168

RP-HPLC analysis of carotenoids profile

170 The carotenoid profile of the extracts was analysed using a Merck Hitachi LaCrom Elite

171 HPLC (Darmstadt, Germany) equipped with a diode-array detector (450 nm) using a

172 LiChroCART RP-18 (5 $\mu \mathrm{m}, 250 \times 4 \mathrm{~mm}$, LiChrospher) column, as described by Couso et al.

173 (2012) with slight modifications. The mobile phase consisted of acetonitrile:water (9:1; v/v)

174 as solvent $\mathrm{A}$ and ethyl acetate as solvent B and the gradient program applied was: 0-16 min,

$175 \quad 0-60 \% \mathrm{~B} ; 16-30 \mathrm{~min}, 60 \% \mathrm{~B} ; 30-32 \min 100 \% \mathrm{~B}$ and $32-35 \mathrm{~min} 100 \%$ A. Identification of

176 the pigments was performed based on their retention times and confirmed by comparison of

177 UV-Vis spectra with those of commercial standards. For quantification, external calibration curves were performed for neoxanthin, violaxanthin, lutein and $\beta$-carotene. All pigment standards were supplied by Sigma-Aldrich (Sintra, Portugal). All HPLC grade solvents were purchased from Fisher Scientific (New Hampshire, USA).

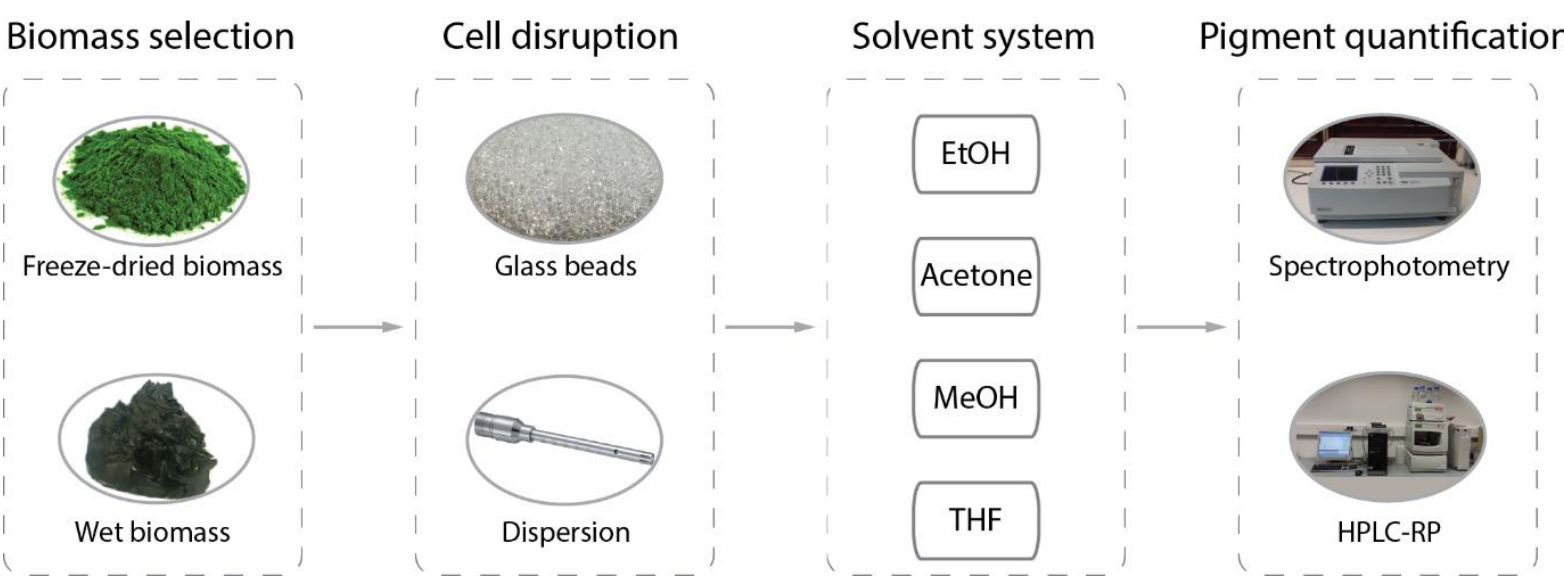

Fig. 1 Workflow of methods used for pigment extraction from Tetraselmis sp. CTP4. All methods were tested on both freeze-dried and wet biomass. The cell disruption was achieved by either mechanical dispersion or grinding with glass beads. Four different solvents were used to extract the pigments, namely ethanol $(\mathrm{EtOH})$, acetone, methanol $(\mathrm{MeOH})$ and tetrahydrofuran (THF). Chlorophyll and carotenoid contents of each extract were analysed by spectrophotometry. Pigment profiles of the four best extracts were analysed by RP-HPLC. All methods were performed in triplicate 

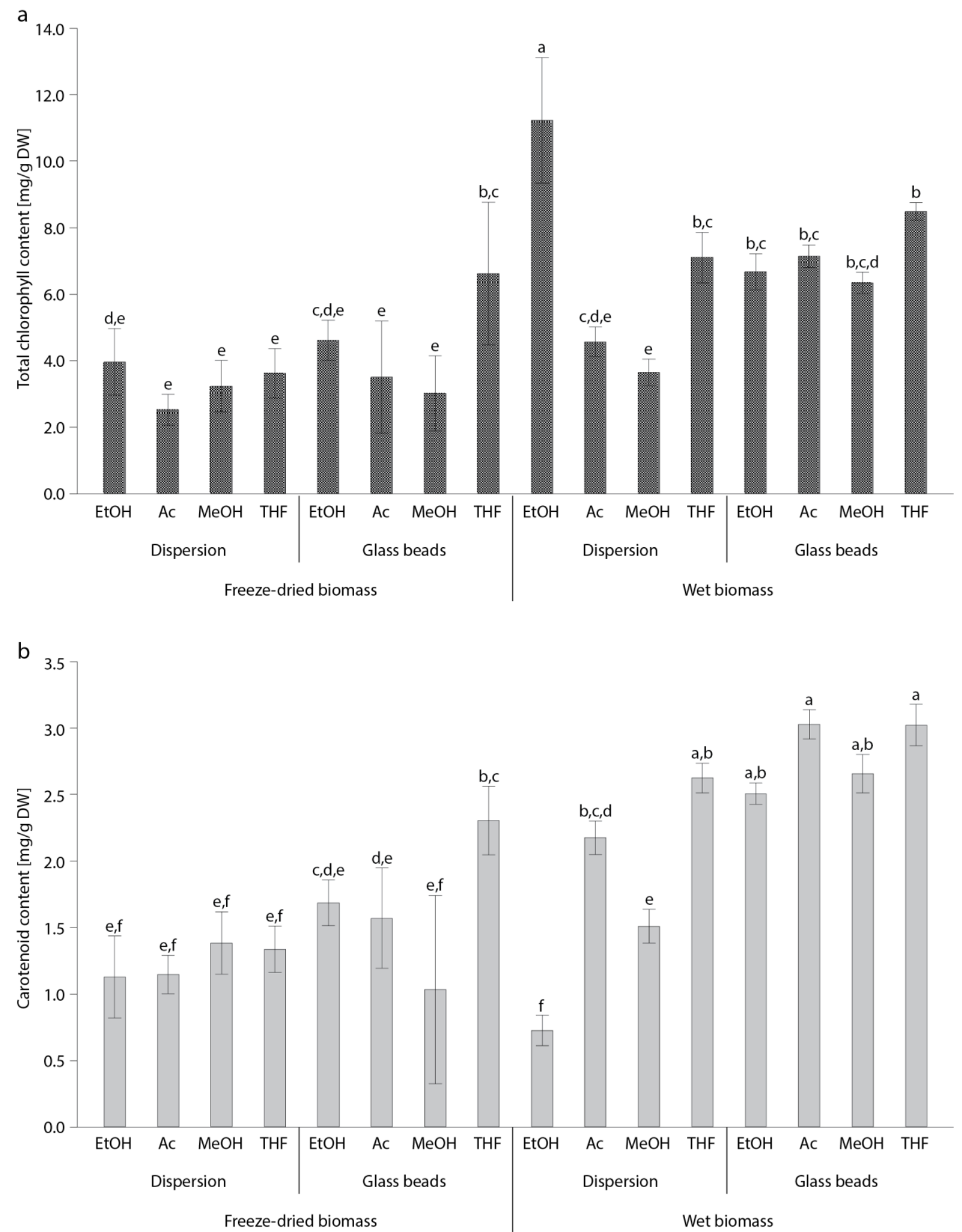

Fig. 2 Total chlorophyll (a) and total carotenoid (b) contents of extracts prepared from 194 lyophilized and wet Tetraselmis sp. CTP4 biomass. To optimize the extraction conditions, 195 different solvents were tested, namely ethanol (EtOH), acetone (Ac), methanol (MeOH) and tetrahydrofuran (THF). Different cell disruption methods were also tested: dispersion or glass bead milling. Each extraction was performed in triplicate and results are reported as means \pm standard deviation. Different letters indicate significant differences $(\mathrm{p}<0.05)$ using one-way ANOVA with post hoc Tukey HSD test 

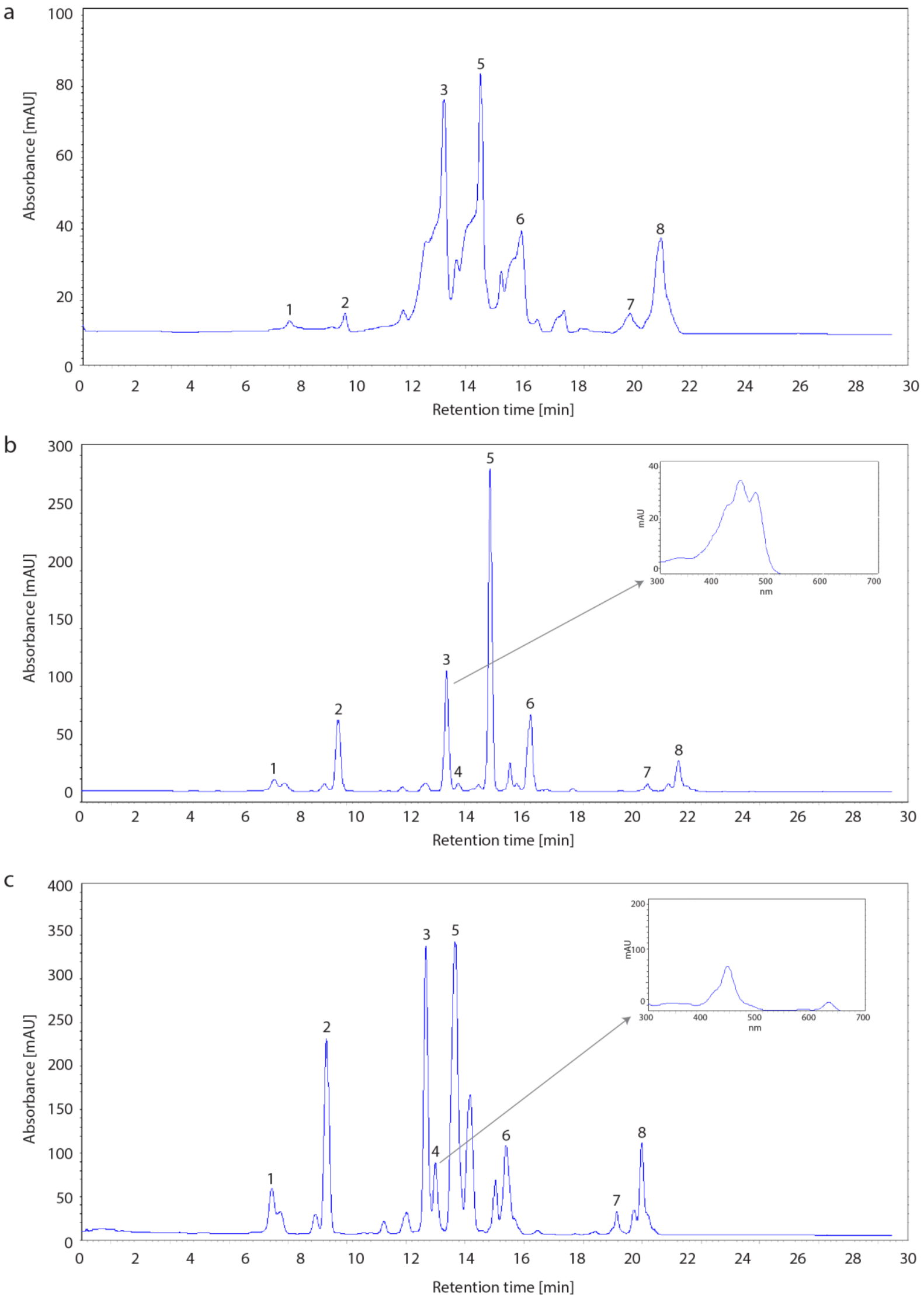

Fig. 3 HPLC chromatograms of pigment extract of Tetraselmis sp. CTP4 at $450 \mathrm{~nm}$. Extraction was carried out from wet biomass using acetone and cell disruption by glass beads. (a) Chromatogram of extracts injected in acetone, showing broad peaks and poorer resolution. (b) Chromatogram of the extract, in methanol, injected immediately after pigment 
extraction revealing well shaped and separated peaks. The spectrum of peak 3 showed the typical profile of lutein (small picture). (c) Injection after $24 \mathrm{~h}$ in methanol showing overlapping of peaks 3 and 4 . The small picture shows the spectrum of peak 4 with an absorbance peak at $680 \mathrm{~nm}$, typical of chlorophyll. The identified pigments were: 1) neoxanthin, 2) violaxanthin, 3) lutein, 4) zeaxanthin, 5) chlorophyll b, 6) chlorophyll a, 7) $\alpha$ carotene, 8) $\beta$-carotene

\section{Results and discussion}

\section{Optimization of pigment extraction of Tetraselmis sp. CTP4}

214

The first parameter addressed in the optimization of pigment extraction was the type of biomass. Both freeze-dried and frozen biomass paste (wet biomass) were analysed, as these are two common types of industrial processing of microalgal biomass. The highest amount of both chlorophylls and carotenoids from Tetraselmis sp. CTP4 was recovered from wet biomass as compared to those from freeze-dried microalgae, up to 3- and 2.5-fold more, respectively (Fig. 2). Freeze-drying has been considered a mild method to dehydrate the biomass without significant losses of pigments. However, long-term storage (> 35 days) at room temperature caused losses of carotenoids in Phaeodactylum tricornutum, and a decreased lutein content in Scenedesmus almeriensis of about 50\% after 20 days [42, 46]. Therefore, the lower recovery of pigments from freeze-dried biomass could be an effect of long-term storage conditions, as samples were processed 31 days after lyophilisation. In addition, extraction from wet biomass brings the advantage of being a simple method that omits the drying step, a costly and time-consuming process.

Tetraselmis sp. CTP4 has medium-sized cells (9-12 $\mu \mathrm{m}$; Pereira et al. 2016) and is known for its strong theca. Therefore, two different mechanical cell disruption methods were applied to ensure complete cell disruption and enhance carotenoid extraction. When freeze-dried biomass was used, differences between both disruption methods are not obvious mainly because the extracted amounts of both chlorophylls and carotenoids were low (Fig. 2). A notable exception was THF that was significantly more efficient as an extracting solvent when using glass beads as a cell disruption method. However, when extraction was done on wet biomass, disruption by glass beads was significantly more efficient than by dispersion, for all pigments (Fig. 2). The only exception was dispersion in combination with THF as solvent, which yielded high chlorophyll and carotenoid contents (Fig. 2). Nonetheless, glass bead-assisted disruption significantly improved pigment recovery from wet biomass of CTP4 (1.5-fold) compared with dispersion (Fig. 2). It is possible that the observed difference is 
partially related to the different time periods used for cell disruption by the two methods. Due to the higher amount of heat generated by the Ultra-Turrax dispersion, the application of this method was limited to 2 cycles of $45 \mathrm{~s}$ while bead milling could be applied for 2 minutes without any noticeable heating of the sample. Since elevated temperatures can lead to metabolites degradation, heating production during cell disruption by Ultra-Turrax can be a strong limitation $[14,15]$. Other authors have found similar results. For example, Taucher et al. (2016) achieved better disruption of Chlorella zofingiensis (cell size range: 2-15 $\mu \mathrm{m}$ ) by ball milling rather than with mechanical dispersion. Another study in Coelastrella sp., an alga with a thick cell wall, reported also bead milling as a successful process for extracting carotenoids [22]. Concerning Tetraselmis, glass bead milling was used to extract carotenoids in only one report [41]. Other studies on Tetraselmis species used cell disruption by sonication $[19,28,33,34,36]$. However, ultrasounds can lead to the cleavage of water to free $\bullet \mathrm{OH}$ and $\bullet \mathrm{H}$ radicals, which can damage the extracted carotenoids, and should therefore be avoided [48]. Another disadvantage of sonication is that it can only be applied to small-sized samples, whereas bead or ball milling have already been implemented at industrial scale. For example, a so called DYNO-mill, was successfully used for the disruption of Tetraselmis wet biomass to isolate protein $[49,50]$. Therefore, a scale-up of this extraction method is conceivable, though involving high-energy consumption. Other industrially scalable methods include high-pressure homogenization, which has also been applied successfully to rupture microalgae including from the Tetraselmis genus [51].

Another important parameter is the selection of an appropriate solvent for an efficient extraction. However, in our study, the choice of solvent appears to be less important since no significant changes in the extraction yields of both chlorophylls and carotenoids were found, when glass beads were used for cell disruption. This might be related to the fact that all the chosen solvents are polar solvents and appropriate for the extraction of these compounds. The best chlorophyll yields were obtained using THF, which led to of $8.14 \pm 0.82 \mathrm{mg} \mathrm{g}^{-1} \mathrm{DW}$. The best extraction yields for all carotenoids from CTP4 were obtained with THF and acetone: $3.02 \pm 0.16$ and $3.03 \pm 0.11 \mathrm{mg} \mathrm{g}^{-1} \mathrm{DW}$, respectively (Fig. 2b). Indeed, acetone is the most commonly used solvent alone or in combination with other solvents for carotenoid extraction from Tetraselmis spp. cells (Table 1). However, when dispersion was used as cell disruption method, the choice of solvent is rather important and THF or acetone were the most efficient for pigment extraction. These results indicate that the right combination of cell disruption and solvent needs to be selected for improved extraction of pigments from 
microalgal biomass. Nevertheless, THF has a tendency to form explosive peroxides for long storage as well as during distillation. Therefore, to minimize this problem, the purchased THF should be protected with an antioxidant molecule, such as butylated hydroxytoluene (BHT) $[52,53]$.

\section{Optimization of individual carotenoid extraction of Tetraselmis sp. CTP4 biomass}

To optimize the selectivity of the extraction methods on individual carotenoids, RP-HPLC was used for analysis. Direct injection of extracts in acetone under the RP-HPLC conditions used in this paper showed broad peaks with shoulders, in particular for the polar xanthophylls, thus, leading to poor quantification (Fig. 3a). Therefore, prior to injection, the solvent of the extracts was changed from acetone to methanol, which resulted in a better resolution of the peaks and good peak integration (Fig. 3b). This observation is in agreement with other publications on RP-HPLC methods for the quantification of microalgal pigments [54-56]. As an example, the absorbance spectrum of lutein is shown with a shoulder at $422 \mathrm{~nm}$, and absorbance maxima at 448 and $476 \mathrm{~nm}$ (Fig. 3b, small picture). However, once the extract was resuspended in methanol, analysis was performed immediately to avoid pigment degradation as methanol is known to promote formation of chlorophyll allomers, which can cause overlapping peaks with lutein (Fig. 3c, Porra et al. 1997). Nevertheless, the focus of the RP-HPLC analysis was on carotenoids rather than chlorophyll. Therefore, only the most efficient extraction methods for carotenoids obtained by spectrophotometry were investigated, namely extractions from wet biomass using acetone or THF and cell disruption using glass beads or mechanical dispersion. RP-HPLC analysis of Tetraselmis sp. CTP4 carotenoid profile showed that the most dominant carotenoids were neoxanthin, violaxanthin, lutein and $\beta$-carotene (Fig. 3a) which is in agreement with reports from other authors for different Tetraselmis species [58]. The quantification of these four carotenoids in the extracts confirmed the results obtained by spectrophotometric analysis: glass bead-assisted extraction led to a 2.4-fold average increase of carotenoids extracted from wet biomass over dispersionbased methods, regardless of the solvent used (Fig. 4). On average, THF was also a better solvent for carotenoid extraction than acetone, when dispersion-based homogenization was used. Overall, THF was more efficient than acetone for the extraction of all carotenoids. However, if the biomass was milled with glass beads, THF was found to be a better solvent for the extraction of lutein and $\beta$-carotene $\left(622 \pm 40\right.$ and $618 \pm 32 \mu \mathrm{g} \mathrm{g}^{-1} \mathrm{DW}$, respectively), but as good as acetone for neoxanthin (38.7-52.3 $\left.\mu \mathrm{g} \mathrm{g}^{-1} \mathrm{DW}\right)$ and violaxanthin (123-139 $\mu \mathrm{g} \mathrm{g}^{-}$ 
$305{ }^{1}$ DW) (Fig. 4). This is in agreement with the solubility tests made by Craft and Soares 306 (1992), who showed that THF was the best solvent for lutein and $\beta$-carotene. Furthermore, in 307 a study on Chlorella sorokiniana, THF was shown to lead to a higher recovery of lutein than 308 acetone [60]. However, considering the commercialization of the extracts for food 309 applications, acetone is preferred, as it is both cheaper and listed as a GRAS (Generally 310 Recognized As Safe) solvent. Moreover, acetone does not require the addition of antioxidants 311 with potential for toxicity such as BHT to maintain its stability [61]. The carotenoid 312 concentrations detected in this study are comparable to those found in the literature for other 313 Tetraselmis species [36, 58], although higher contents have been reported in the heat-tolerant 314 microalga Tetraselmis sp. DS3 [41]. However, carotenoid contents are often dependent on the 315 species and its cultivation conditions, which might explain the differences observed. This is 316 an on-going investigation in this species by our group. 

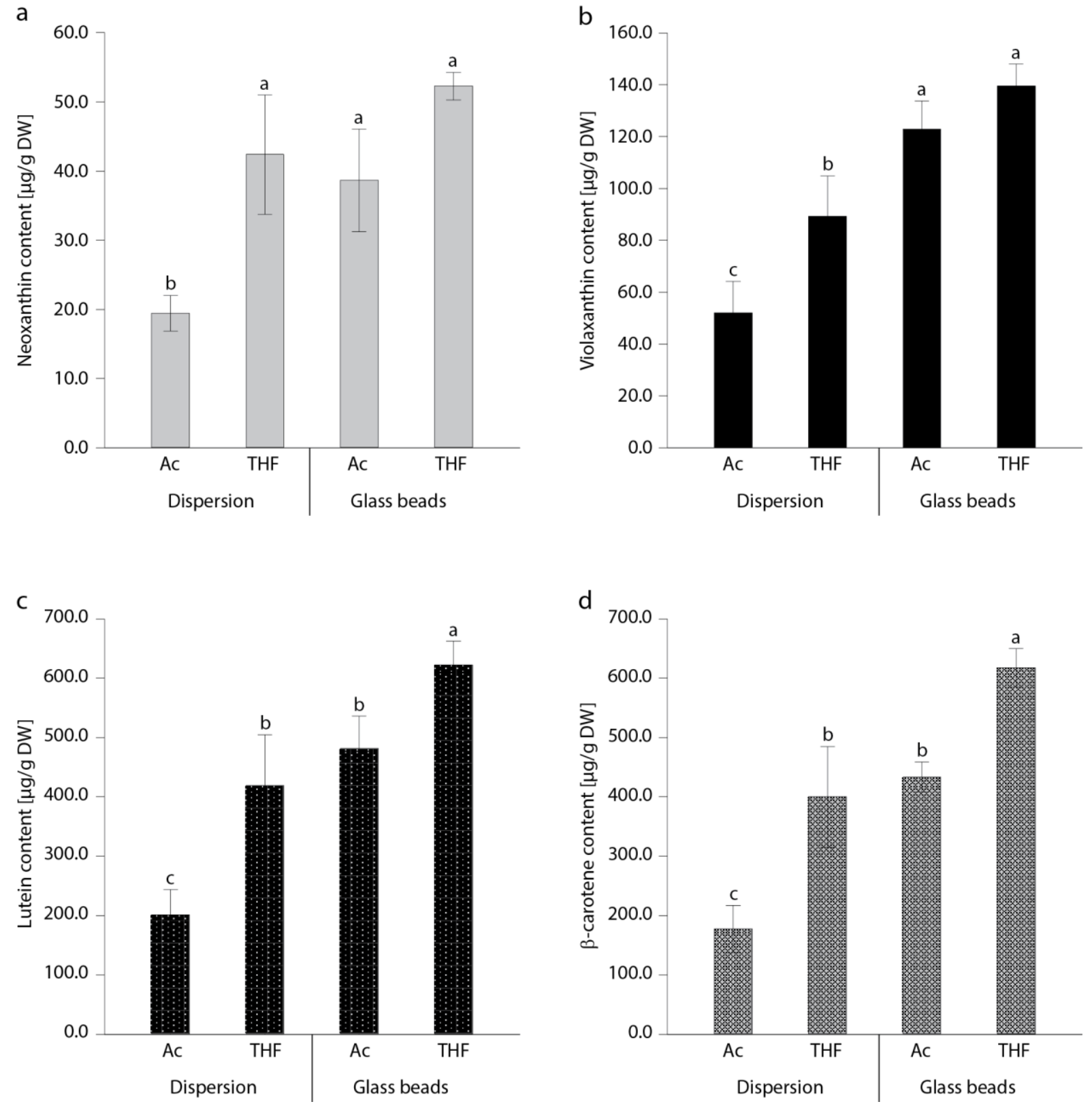

318 Fig. 4 Quantification of neoxanthin (a), violaxanthin (b), lutein (c) and $\beta$-carotene (d) 319 extracted from wet biomass of Tetraselmis sp. CTP4. Carotenoids were extracted using acetone (Ac) or tetrahydrofuran (THF) and glass-bead milled or mechanically dispersed to promote cell disruption. This experiment was performed in triplicate and the means \pm standard deviation is shown for all results. For each figure, different letters indicate significant differences $(p<0.05)$ using one-way ANOVA with post hoc Tukey HSD test

\section{Conclusions}

326 Tetraselmis sp. CTP4 proved to be a good candidate for the development of a suitable method

327 for carotenoid extraction, as it contained significant amounts of extractable carotenoids,

328 particularly lutein and $\beta$-carotene, two pigments with high market value as ingredients in

329 food, feed, nutraceutical and cosmeceutical formulations. The best method for carotenoid 
extraction was a combination of disruption by glass beads using THF applied to wet biomass as storage of freeze-dried biomass might have led to pigment degradation. However, a combination of disruption by glass beads using acetone applied to wet biomass was almost as efficient and is less costly and less time consuming than using freeze-dried biomass or THF as solvent. These characteristics and the scalability of glass bead milling make this method industrially applicable. Furthermore, as it is easy to carry out, it could become a common protocol for carotenoid extraction from mechanically robust microalgae, which would greatly facilitate the comparison between different species.

\section{Compliance with ethical standards}

Conflict of Interest The authors declare that they have no conflict of interest.

\section{References}

1. Varela JC, Pereira H, Vila M, León R (2015) Production of carotenoids by microalgae: achievements and challenges. Photosynth Res 125:423-436 . doi: 10.1007/s11120015-0149-2

2. Johnson EJ (2002) The role of carotenoids in human health. Nutr Clin Care 5:56-65 . doi: 10.1046/j.1523-5408.2002.00004.x

3. Fiedor J, Burda K (2014) Potential role of carotenoids as antioxidants in human health and disease. Nutrients 6:466-488 . doi: 10.3390/nu6020466

4. Eggersdorfer M, Wyss A (2018) Carotenoids in human nutrition and health. Arch Biochem Biophys 652:18-26 . doi: 10.1016/j.abb.2018.06.001

5. Vílchez C, Forján E, Cuaresma M, Bédmar F, Garbayo I, Vega JM (2011) Marine carotenoids: Biological functions and commercial applications. Mar Drugs 9:319-333 . doi: 10.3390/md9030319

6. Guedes AC, Amaro HM, Malcata FX (2011) Microalgae as sources of carotenoids. Mar Drugs 9:625-644 . doi: 10.3390/md9040625

7. Borowitzka MA (2013) High-value products from microalgae-their development and commercialisation. J Appl Phycol 25:743-756 . doi: 10.1007/s10811-013-9983-9

8. Sánchez JF, Fernández JM, Acién FG, Rueda A, Pérez-Parra J, Molina E (2008) Influence of culture conditions on the productivity and lutein content of the new strain Scenedesmus almeriensis. Process Biochem 43:398-405 . doi: 
9. Ben-Amotz A, Shaish A, Avron M (1989) Mode of action of the massively accumulated $\beta$-carotene of Dunaliella bardawil in protecting the alga against damage by excess irradiation. Plant Physiol 91:1040-1043 . doi: 10.1104/pp.91.3.1040

10. Mulders KJM, Lamers PP, Martens DE, Wijffels RH (2014) Phototrophic pigment production with microalgae: biological constraints and opportunities. J Phycol 50:229_ 242 . doi: 10.1111/jpy.12173

11. Siegel BZ, Siegel SM (1973) The chemical composition of algal cell walls. CRC Crit Rev Microbiol 3:1-26 . doi: 10.3109/10408417309108743

12. Becker B, Melkonian M, Kamerling JP (1998) The cell wall (theca) of Tetraselmis

14. Saini RK, Keum YS (2018) Carotenoid extraction methods: A review of recent

18. Goiris K, Muylaert K, Fraeye I, Foubert I, De Brabanter J, De Cooman L (2012)

19. Goiris K, Van Colen W, Wilches I, León-Tamariz F, De Cooman L, Muylaert K 
microalgae. Algal Res 7:51-57 . doi: 10.1016/j.algal.2014.12.002

20. Batista AP, Gouveia L, Bandarra NM, Franco JM, Raymundo A (2013) Comparison of microalgal biomass profiles as novel functional ingredient for food products. Algal Res 2:164-173 . doi: 10.1016/j.algal.2013.01.004

21. Mulders KJM, Weesepoel Y, Bodenes P, Lamers PP, Vincken J, Martens DE, Gruppen H, Wijffels RH (2015) Nitrogen-depleted Chlorella zofingiensis produces astaxanthin, ketolutein and their fatty acid esters: a carotenoid metabolism study. J Appl Phycol 27:125-140 . doi: 10.1007/s10811-014-0333-3

22. Hu CW, Chuang L Te, Yu PC, Chen CNN (2013) Pigment production by a new thermotolerant microalga Coelastrella sp. F50. Food Chem 138:2071-2078 . doi: 10.1016/j.foodchem.2012.11.133

23. Ahmed F, Fanning K, Netzel M, Turner W, Li Y, Schenk PM (2014) Profiling of carotenoids and antioxidant capacity of microalgae from subtropical coastal and brackish waters. Food Chem 165:300-306 . doi: 10.1016/j.foodchem.2014.05.107

24. León R, Vila M, Hernánz D, Vílchez C (2005) Production of phytoene by herbicidetreated microalgae Dunaliella bardawil in two-phase systems. Biotechnol Bioeng 92:695-701 . doi: 10.1002/bit.20660

25. Lamers PP, van de Laak CCW, Kaasenbrood PS, Lorier J, Janssen M, De Vos RCH, Bino RJ, Wijffels RH (2010) Carotenoid and fatty acid metabolism in light-stressed Dunaliella salina. Biotechnol Bioeng 106:638-648 . doi: 10.1002/bit.22725

26. Huang JJ, Bunjamin G, Teo ES, Ng DB, Lee YK (2016) An enclosed rotating floating photobioreactor (RFP) powered by flowing water for mass cultivation of photosynthetic microalgae. Biotechnol Biofuels 9:218 . doi: 10.1186/s13068-0160633-8

27. Castro-Puyana M, Herrero M, Urreta I, Mendiola JA, Cifuentes A, Ibáñez E, SuárezAlvarez S (2013) Optimization of clean extraction methods to isolate carotenoids from the microalga Neochloris oleoabundans and subsequent chemical characterization using liquid chromatography tandem mass spectrometry. Anal Bioanal Chem 405:4607-4616 . doi: 10.1007/s00216-012-6687-y

28. Garrido JL, Rodríguez F, Zapata M (2009) Occurence of loroxanthin, loroxanthin decenoate, and loroxanthin dodecenoate in Tetraselmis species (Prasinophyceae, Chlorophyta). J Phycol 45:366-374 . doi: 10.1111/j.1529-8817.2009.00660.x

29. Lourenço SO, Marquez UML, Mancini-Filho J, Barbarino E, Aidar E (1997) Changes in biochemical profile of Tetraselmis gracilis I. Comparison of two culture media. 
Aquaculture 148:153-168 . doi: 10.1016/S0044-8486(96)01416-0

30. Dahmen-Ben Moussa I, Chtourou H, Karray F, Sayadi S, Dhouib A (2017) Nitrogen or phosphorus repletion strategies for enhancing lipid or carotenoid production from Tetraselmis marina. Bioresour Technol 238:325-332 . doi: 10.1016/j.biortech.2017.04.008

31. Sansone C, Galasso C, Orefice I, Nuzzo G, Luongo E, Cutignano A, Romano G, Brunet C, Fontana A, Esposito F, Ianora A (2017) The green microalga Tetraselmis suecica reduces oxidative stress and induces repairing mechanisms in human cells. Nat Publ Gr 1-12 . doi: 10.1038/srep41215

32. Abiusi F, Sampietro G, Marturano G, Biondi N, Rodolfi L, D’Ottavio M, Tredici MR (2014) Growth, photosynthetic efficiency, and biochemical composition of Tetraselmis suecica F\&M-M33 grown with LEDs of different colors. Biotechnol Bioeng 111:956964 . doi: 10.1002/bit.25014

33. Wright SW, Jeffrey SW, Mantoura RFC (1997) Evaluation of methods and solvents for pigment extraction. In: Jeffrey SW, Wright SW, Mantoura RFC (eds) Phytoplankton pigments in oceanogpaphy: guidelines to modern methods. UNESCO Publishing, Paris, pp 261-282

34. Zapata M, Rodríguez F, Garrido JL (2000) Separation of chlorophylls and carotenoids from marine phytoplankton: a new HPLC method using a .... Mar Ecol Prog Ser 195:29-45 . doi: 10.3354/meps195029

35. Borghini F, Colacevich A, Bergamino N, Micarelli P, Dattilo AM, Focardi S, Focardi S, Loiselle SA (2009) The microalgae Tetraselmis suecica in mesocosms under different light regimes. Chem Ecol 25:345-357 . doi: 10.1080/02757540903193148

36. Di Lena G, Casini I, Lucarini M, Lombardi-Boccia G (2019) Carotenoid profiling of five microalgae species from large-scale production. Food Res Int 120:810-818 . doi: 10.1016/j.foodres.2018.11.043

37. El-Kassas HY, El-Sheekh MM (2016) Induction of the synthesis of bioactive compounds of the marine alga Tetraselmis tetrathele (West) Butcher grown under salinity stress. Egypt J Aquat Res 42:385-391 . doi: 10.1016/j.ejar.2016.10.006

38. Egeland ES, Eikrem W, Throndsen J, Wilhelm C, Zapata M, Liaaen-Jensen S (1995) Carotenoids from further prasinophytes. Biochem Syst Ecol 23:747-755 . doi: 10.1016/0305-1978(95)00075-5

39. Dammak M, Hadrich B, Miladi R, Barkallah M, Hentati F, Hachicha R, Laroche C, Michaud P, Fendri I, Abdelkafi S (2017) Effects of nutritional conditions on growth 
and biochemical composition of Tetraselmis sp. Lipids Health Dis 16:41 . doi: 10.1186/s12944-016-0378-1

40. Maadane A, Merghoub N, Ainane T, El Arroussi H, Benhima R, Amzazi S, Bakri Y, Wahby I (2015) Antioxidant activity of some Moroccan marine microalgae: Pufa profiles, carotenoids and phenolic content. J Biotechnol 215:13-19 . doi: 10.1016/j.jbiotec.2015.06.400

41. Tsai H-P, Chuang L-T, Chen C-NN (2016) Production of long chain omega-3 fatty acids and carotenoids in tropical areas by a new heat-tolerant microalga Tetraselmis sp. DS3. Food Chem 192:682-690 . doi: 10.1016/j.foodchem.2015.07.071

42. Cerón-García M del C, Campos-Pérez I, Macías-Sánchez MD, Bermejo-Román R, Fernández-Sevilla JM, Molina-Grima E (2010) Stability of carotenoids in Scenedesmus almeriensis biomass and extracts under various storage conditions. J Agric Food Chem 58:6944-6950 . doi: 10.1021/jf100020s

43. Schulze PSC, Carvalho CFM, Pereira H, Gangadhar KN, Schüler LM, Santos TF, Varela JCS, Barreira L (2017) Urban wastewater treatment by Tetraselmis sp. CTP4 (Chlorophyta). Bioresour Technol 223:175-183 . doi: 10.1016/j.biortech.2016.10.027

44. Lichtenthaler HK, Wellburn AR (1983) Determinations of total carotenoids and chlorophylls a and b of leaf extracts in different solvents. Biochem Soc Trans 11:591592 . doi: 10.1042/bst0110591

45. Couso I, Vila M, Vigara J, Cordero BF, Vargas MÁ, Rodríguez H, León R (2012) Synthesis of carotenoids and regulation of the carotenoid biosynthesis pathway in response to high light stress in the unicellular microalga Chlamydomonas reinhardtii. Eur J Phycol 47:223-232 . doi: 10.1080/09670262.2012.692816

46. Ryckebosch E, Muylaert K, Eeckhout M, Ruyssen T, Foubert I (2011) Influence of drying and storage on lipid and carotenoid stability of the microalga Phaeodactylum tricornutum. J Agric Food Chem 59:11063-11069 . doi: 10.1021/jf2025456

47. Taucher J, Baer S, Schwerna P, Hofmann D, Hümmer M, Buchholz R, Becker A (2016) Cell disruption and pressurized liquid extraction of carotenoids from microalgae. Thermodyn Catal 7:1-7 . doi: 10.4172/2158-7544.1000158

48. Petrier C, Jeunet A, Luche JL, Reverdy G (1992) Unexpected frequency effects on the rate of oxidative processes induced by ultrasound. J Am Chem Soc 114:3148-3150 . doi: $10.1021 / \mathrm{ja} 00034 \mathrm{a} 077$

49. Geciova J, Bury D, Jelen P (2002) Methods for disruption of microbial cells for potential use in the dairy industry - a review. Int Dairy J 12:541-553 . doi: 
50. Schwenzfeier A, Wierenga PA, Gruppen H (2011) Isolation and characterization of soluble protein from the green microalgae Tetraselmis sp. Bioresour Technol 102:9121-9127 . doi: 10.1016/j.biortech.2011.07.046

51. Spiden EM, Yap BHJ, Hill DRA, Kentish SE, Scales PJ, Martin GJO (2013) Bioresource Technology Quantitative evaluation of the ease of rupture of industrially promising microalgae by high pressure homogenization. Bioresour Technol 140:165171 . doi: 10.1016/j.biortech.2013.04.074

52. Khachik F, Beecher GR, Whittaker NF (1986) Separation, identification, and quantification of the major carotenoid and chlorophyll constituents in extracts of several green vegetables by liquid chromatography. J Agric Food Chem 34:603-616 . doi: 10.1021/jf00070a006

53. Rivera S, Canela R (2012) Influence of sample processing on the analysis of carotenoids in maize. Molecules 17:11255-11268 . doi: 10.3390/molecules170911255

54. van Leeuwe MA, Villerius LA, Roggeveld J, Visser RJW, Stefels J (2006) An optimized method for automated analysis of algal pigments by HPLC. Mar Chem 102:267-275 . doi: 10.1016/j.marchem.2006.05.003

55. Zapata M, Garrido JL (1991) Influence of injection conditions in reversed-phase highperformance liquid chromatography of chlorophylls and carotenoids. Chromatographia 31:589-594 . doi: 10.1007/BF02279480

56. Wright S, Jeffrey S, Mantoura R, Llewellyn C, Bjornland T, Repeta D, Welschmeyer N (1991) Improved HPLC method for the analysis of chlorophylls and carotenoids from marine phytoplankton. Mar Ecol Prog Ser 77:183-196 . doi: 10.3354/meps077183

57. Porra RJ, Pfündel EE, Engel N (1997) Metabolism and function of photosynthetic pigments. In: Jeffrey SW, Wright SW, Mantoura RFC (eds) Phytoplankton pigments in oceanogpaphy: guidelines to modern methods. UNESCO Publishing, Paris, pp 85-126

58. Ahmed F, Fanning K, Netzel M, Turner W, Li Y, Schenk PM (2014) Profiling of carotenoids and antioxidant capacity of microalgae from subtropical coastal and brackish waters. Food Chem 165:300-306 . doi: 10.1016/j.foodchem.2014.05.107

59. Craft NE, Soares JH (1992) Relative solubility, stability, and absorptivity of lutein and $\beta$-carotene in organic solvents. J Agric Food Chem 40:431-434 . doi:

\subsection{1/jf00015a013}

60. Chen CY, Jesisca, Hsieh C, Lee DJ, Chang CH, Chang JS (2016) Production, 
534

535

536

537

538

539

extraction and stabilization of lutein from microalga Chlorella sorokiniana MB-1. Bioresour Technol 200:500-505 . doi: 10.1016/j.biortech.2015.10.071

61. EFSA ANS (2012) Scientific Opinion on the re-evaluation of butylated hydroxytoluene BHT (E 321) as a food additive. EFSA J 10:2588 . doi: 10.2903/j.efsa.2012.2588 